\title{
Mechanistic modeling of different types of surge tanks and draft tubes for hydropower plants
}

\author{
Madhusudhan Pandey, Bernt Lie \\ TMCC, University of South-Eastern Norway, Bernt.Lie@usn.no
}

\begin{abstract}
OpenHPL is an open-source hydropower library consisting of models for hydropower components that are developed based on mass and 1D momentum balance. It consists of mechanistic models for the flow of water in filled pipes (inelastic and elastic walls, incompressible and compressible water), a mechanistic model of a Francis turbine (including design of turbine parameters), friction models, etc. This paper includes an extension of OpenHPL with mechanistic models of different types of surge tanks (sharp orifice type, throttle valve surge tank, air-cushion surge tank) and draft tubes (conical diffusers and Moody spreading pipes). The simulated response of the models is presented using a case study of real hydro power plants.

Keywords: surge tanks, draft tubes, air-cushion surge tank, throttle valve surge tank, conical diffuser, Moody spreading pipes
\end{abstract}

\section{Introduction}

\subsection{Background}

The electricity generation from renewables has increased because of the rise in coal prices, oil insecurity, climatic concern (Brown, 2012), and the nuclear power debate (Wikipedia, 2019). There is a demand for renewablesources economy over the coal-fired economy (Brown, 2012). The renewable energy sources are a combination of intermittent and dispatchable energy sources. Intermittent sources like solar, wind, and tidal power plants exhibit fluctuating power production that creates an imbalance between generation and load. In this regard, renewable dispatchable sources like hydro power plants play a significant role in balancing out the variability caused by intermittent sources. Current hydropower modeling, design, and analysis tools are limited and available commercially. Freely available tools include CASiMiR-Hydropower ${ }^{1}$, LVTrans $^{2}$, and OpenHPL ${ }^{3}$, while commercial tools include $\mathrm{Alab}^{4}$ and Modelon Hydro Power Library (HPL) ${ }^{5}$. In this regards, it drives motivation for open-source hydro power library development for modeling, design, and

\footnotetext{
${ }^{1}$ http://www.casimir-software.de/save_download.php?language $=2$

${ }^{2} \mathrm{http}: / /$ svingentech.no/about\%20lvtrans.html

${ }^{3}$ https://github.com/simulatino/OpenHPL

${ }^{4}$ http://www.alab.no/Alab-Hydropower-Software/FunctionalityAlab-Hydropower-Software/Operation-simulation-with-waterway

${ }^{5}$ https://www.modelon.com/library/hydro-power-library/
}

analysis.

\subsection{Previous studies}

A mechanistic model of hydropower systems has been developed in (Splavska et al., 2017) using mass and 1D linear momentum balance which leads to a Modelica ${ }^{6}$ based open-source hydropower library OpenHPL, and was initiated in a PhD study (Vytvytskyi, 2019). OpenHPL is under development at the University of South-Eastern Norway. Currently, OpenHPL has units for flow of water in filled pipes (inelastic and elastic walls, incompressible and compressible water) (Vytvytsky and Lie, 2017), a mechanistic model of a Francis turbine (including design of turbine parameters), friction models, etc (Vytvytskyi and Lie, 2018). The library also has draft models for a Pelton turbine, Francis turbine friction model, surge shaft, open channel flow, and a hydrology model. In addition, some accompanying work on analysis tools has been developed in scripting languages (Python, Julia) related to state estimation, structural analysis, etc (Vytvytskyi and Lie, 2019b). The library has been tested on real power plant data (Vytvytskyi and Lie, 2019a). The library is designed to interface to other Modelica libraries, e.g., libraries with generator models, electric grid, etc., for example, OpenHPL can be integrated with PVSystems ${ }^{7}$ for photovoltaics as in (Pandey and Lie, 2020).

In this regard it is of interest to further develop units for OpenHPL. This paper primarily focuses on mechanistic models of surge tanks and draft tubes. The simple surge tank mechanistic model developed in (Splavska et al., 2017) is further enhanced by a sharp orifice type surge tank and a throttle valve surge tank considering hydraulic resistance in the inlet to the surge tank. The surge tank model is also further enhanced using air-cushion surge tank as a closed surge tank mechanistic model. A further extension to the library includes mechanistic models of draft tubes: conical diffuser and moody spreading pipes.

\subsection{Outline of the paper}

The paper is organized as follows. Model developments for surge tanks and draft tubes are provided in Section 2. The simulated response for the developed mechanistic model for surge tanks and draft tubes are presented in Section 3. Conclusions and future work are sketched in

\footnotetext{
${ }^{6}$ https://www.modelica.org/

${ }^{7}$ https://github.com/raulrpearson/PVSystems
} 


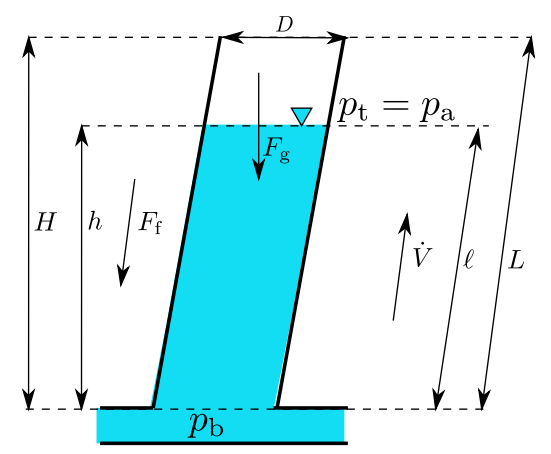

Figure 1. Simple surge tank with geometrical dimensions of height $H$, length $L$, and diameter $D$. The height of liquid level inside the surge tank is $h$ with slanted length to be $\ell$. The volumetric flow rate inside the surge tank is $\dot{V}$ with $F_{\mathrm{f}}$ as fluid friction. $F_{\mathrm{g}}$ is the gravitational force due to fluid mass $m$ inside the surge tank. $p_{\mathrm{b}}$ is the bottom pressure and $p_{\mathrm{t}}$ is the top pressure equivalent to atmospheric pressure $p_{\mathrm{a}}$ for a free-fluid surface. For a hydropower system, we considered fluid inside the surge tank to be water with color as blue.

\section{Section 4}

\section{Model Developement}

Two main assumptions were made while developing models for hydro power units. First, we consider incompressible water flow inside the units. Second, we consider the inelastic pipe for modeling all types of surge tanks and draft tubes.

\subsection{Surge tanks}

A surge tank is usually placed between an intake and a penstock pipe in a hydro power system. The prime benefit of a surge tank is to provide a low-pressure region to dissipates pressure energy released during the sudden opening and closing of the turbine valve. Depending on the location and head, the surge tank can be of open type (water surface at atmospheric pressure) or closed type (water surface in contact with pressurized gas/air).

\subsubsection{Simple surge tank}

A simple surge tank is shown in Fig. 1.

The mass and momentum balance for a dynamical system can be expressed as in (Lie, 2017a, p. 87-88, 226-227)

$$
\begin{aligned}
\frac{d m}{d t} & =\dot{m}_{\mathrm{i}}-\dot{m}_{\mathrm{e}} \\
\frac{d \mathscr{M}}{d t} & =\dot{\mathscr{M}}_{\mathrm{i}}-\dot{\mathscr{M}}_{\mathrm{e}}+F,
\end{aligned}
$$

where subscript $i$ and e refers to influent and effluent properties, respectively. $m, \mathscr{M}$ and $F$ represents mass, linear momentum and force acted-upon in a dynamical system. If $\dot{m}$ and $\dot{\mathscr{M}}$ are mass flow rate and momentum flow rate for a system with single entry and single exit, it is commonly written as $\dot{m}_{\mathrm{i}}-\dot{m}_{\mathrm{e}}=\dot{m}$ and $\dot{M}_{\mathrm{i}}-\dot{\mathscr{M}}_{\mathrm{e}}=\dot{\mathscr{M}}$.

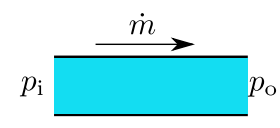

Figure 2. A hydropower unit, for example a simple rigid pipe, with ideal fluid (water) flow from a inlet pressure point $p_{\mathrm{i}}$ to outlet pressure $p_{\mathrm{o}}$ with $\dot{m}$ as $a$ flow variable. The pressure point inside the pipe is considered to be a across variable.

For surge tanks, if $\dot{m}$ and $\dot{\mathscr{M}}$ represents water mass flow rate and momentum flow rate of water inside the surge tank, respectively, then,

$$
\begin{aligned}
\frac{d m}{d t} & =\dot{m} \\
\frac{d \mathscr{M}}{d t} & =\dot{\mathscr{M}}+F .
\end{aligned}
$$

The modeling of hydropower units in OpenHPL is considered using $\dot{m}$ as a flow variable and pressure $p$ at any point in a unit as a across variable ${ }^{8}$.

Figure 2 shows a connector for a hydropower unit created for OpenHPL. While developing a unit, for example a surge tank in our case, mathematical terms in mass and momentum balances as expressed in Eq. 1 and Eq. 2 should be reduced using algebraic variables to $\dot{m}, p_{\mathrm{b}}$, and $p_{\mathrm{t}}$. For the surge tank we have $p_{\mathrm{i}}=p_{\mathrm{b}}$ and $p_{\mathrm{o}}=p_{\mathrm{t}}$ for a volumetric flow $\dot{V}$ sign convention to be positive in the upward direction as in Fig. 1.

The mass balance equation represented in Eq. 1 can be represented by series of algebraic equations. The mass of water inside the surge tank leads to,

$$
\begin{aligned}
m & =\rho A \ell \\
\ell & =\frac{h}{\cos \theta} \\
A & =\frac{\pi D^{2}}{4},
\end{aligned}
$$

and the mass flow rate leads to,

$$
\dot{m}=\rho \dot{V},
$$

where $A$ and $\theta$ represents cross-sectional area and slant angle of a cylindrical surge tank with diameter $D$. $\rho$ represents density of the fluid. $h$ and $\dot{V}$ are differential variable with initial height of water level inside the surge tank as $h_{o}$ and initial discharge to the surge tank as $\dot{V}_{o}$. Similarly, the momentum balance equation in Eq. 2 can be represented by a series of algebraic equations as,

$$
\begin{aligned}
\mathscr{M} & =m v \\
v & =\frac{\dot{V}}{A} \\
\dot{\mathscr{M}} & =\dot{m} v \\
F & =F_{\mathrm{p}}-F_{\mathrm{f}}-F_{\mathrm{g}},
\end{aligned}
$$

${ }^{8}$ The across and flow variables are used for creating a connectors in Modelica language. For more details, please see https://mbe.modelica.university/components/connectors/ . 
where $v$ is the velocity of water inside the surge tank in the direction of $\dot{V}$ and $F$ is the total force acting inside the surge tank in the direction of $v . F_{\mathrm{p}}$ is the force exerted due to pressure difference $p_{\mathrm{b}}-p_{\mathrm{t}}$. $F_{\mathrm{f}}$ is the fluid friction acting opposite in the direction of $v$, and $F_{\mathrm{g}}$ is directed downward due to gravity.

The pressure force exerted in the normal direction of $A$ is given by,

$$
F_{\mathrm{p}}=\left(p_{\mathrm{b}}-p_{\mathrm{t}}\right) A
$$

Furthermore, the fluid friction $F_{\mathrm{f}}$ is calculated as,

$$
\begin{aligned}
F_{\mathrm{f}} & =\frac{K^{\prime \prime \prime} A_{\mathrm{w}} f_{\mathrm{D}}}{4} \\
A_{\mathrm{W}} & =\pi D \ell \\
K^{\prime \prime \prime} & =\frac{\rho \dot{V}|\dot{V}|}{2 A^{2}},
\end{aligned}
$$

where $K^{\prime \prime \prime}$ is the kinetic energy of the fluid per volume which is proportional to the quadratic variation of $\dot{V}$ and $v$. The expression for $K^{\prime \prime \prime}$ is $\frac{\rho v|v|}{2}$. The absolute value for $v$ and $\dot{V}$ allow for reversing direction of water flow. $A_{\mathrm{w}}$ represent the wetted area due to water flow inside the surge tank given by an expression $A_{\mathrm{w}}=\pi D \ell$. In Eq. $12, f_{\mathrm{D}}$ represents Darcy's friction factor given by an implicit expression in the Colebrook-White equation (Colebrook and White, 1937; Colebrook et al., 1939) for transient fullfluid flow in the conduit. There exists several explicit approximation for $f_{\mathrm{D}}$ that requires less computation as listed in (Lie, 2017a, p. 239). For OpenHPL, we are using the explicit approximation of Colebrook-White equation from (Swanee and Jain, 1976),

$$
\frac{1}{\sqrt{f_{\mathrm{D}}}}=-2 \log _{10}\left(\frac{\varepsilon / D}{3.7}+\frac{5.7}{N_{\mathrm{Re}}^{0.9}}\right),
$$

for $N_{\operatorname{Re}}=\left(2300-10^{8}\right)$ and $\varepsilon / D=\left(10^{-5}-0.005\right)$, where $\varepsilon$ is a conduit roughness height and $N_{\operatorname{Re}}$ is the Reynolds number expressed by $N_{\mathrm{Re}}=\frac{\rho|v| D}{\mu}$. Here, $\mu$ represents kinematic viscosity of the fluid.

For laminar flow, $f_{\mathrm{D}}=\frac{64}{N_{\mathrm{Re}}}$ with $N_{\mathrm{Re}}<2100$. The region for the fluid with $2100 \leq N_{\operatorname{Re}}<2300$ is a transition flow interpolated with a $4^{\text {th }}$ order polynomial equation.

The expression for force due to gravity is given as,

$$
F_{\mathrm{g}}=m g \cos \theta \text {. }
$$

Equation 1 to 16 represents Differential Algebraic Equations (DAEs) for the mechanistic modeling of simple surge tank represented in Fig. 1 and can be solved using equation based modeling language like Modelica.

\subsubsection{Sharp orifice type surge tank}

The model of the simple surge tank can be further modified using a sharp orifice hydraulic obstruction inside the surge tank as represented in Fig. 3.

To model the sharp orifice type surge tank we employ the generalized friction factor for sharp orifice fitting as

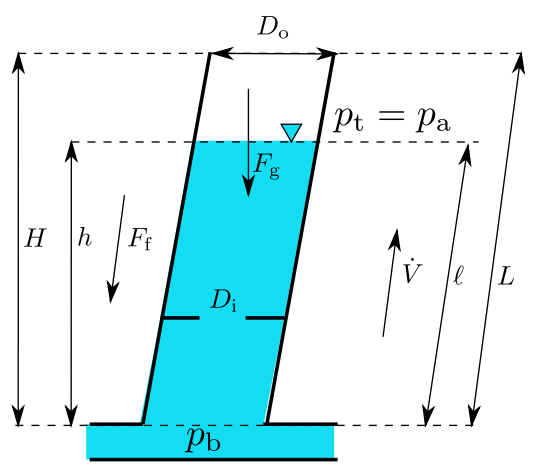

Figure 3. Sharp orifice type surge tank with a sharp orifice of diameter $D_{\mathrm{i}}$ as shown by horizontal perturbation bars inside the surge tank. The sharp orifice acts as a hydraulic obstruction for water flowing inside the surge tank.

given in (Lie, 2017a, p. 246). The expression for fluid friction force represented by Eq. 12 needs a correction term due to the sharp orifice. The frictional force exerted due to sharp orifice can be calculated using an expression for a pressure drop expression as given in (Lie, 2017a, p. 244). The overall frictional force for the sharp orifice type surge tank is now calculated by the expression as,

$$
F_{\mathrm{f}}=\frac{K^{\prime \prime \prime} A_{\mathrm{w}} f_{\mathrm{D}}}{4}+\frac{1}{2} \rho v|v| A \phi_{\mathrm{so}}
$$

where $A$ is the cross-sectional area of the sharp orifice type surge tank with diameter $D_{o}$ which is equivalent to the simple surge tank with diameter noted with symbol $D$, and $\phi_{\text {so }}$ is a generalized friction factor. $\phi_{\text {so }}$ depends on $N_{\operatorname{Re}}$, and the diameter of the surge tank and the orifice.

For $N_{\mathrm{Re}}<2500$ :

$$
\phi_{\text {so }}=\left[2.72+\left(\frac{D_{\mathrm{i}}}{D_{\mathrm{o}}}\right)^{2}\left(\frac{120}{N_{\mathrm{Re}}}-1\right)\right] \cdot \phi_{\mathrm{so}}^{0}
$$

For $N_{\operatorname{Re}} \geq 2500$ :

$$
\phi_{\mathrm{so}}=\left[2.72+\left(\frac{D_{\mathrm{i}}}{D_{\mathrm{o}}}\right)^{2} \cdot \frac{4000}{N_{\mathrm{Re}}}\right] \cdot \phi_{\mathrm{so}}^{0}
$$

where,

$$
\phi_{\mathrm{so}}^{0}=\left[1-\left(\frac{D_{\mathrm{i}}}{D_{\mathrm{o}}}\right)^{2}\right]\left[\left(\frac{D_{\mathrm{i}}}{D_{\mathrm{o}}}\right)^{4}-1\right] .
$$

Equation 1 to 11 , Eq.17, and Eq.13 to 16 represent DAEs for the mechanistic model of the sharp orifice type surge tank.

\subsubsection{Throttle valve surge tank}

To model a throttle valve surge tank we employ a similar method for correction of fluid frictional force as in the case of a sharp orifice type surge tank. A schematic diagram for throttle valve surge tank is given in Fig. 4. 


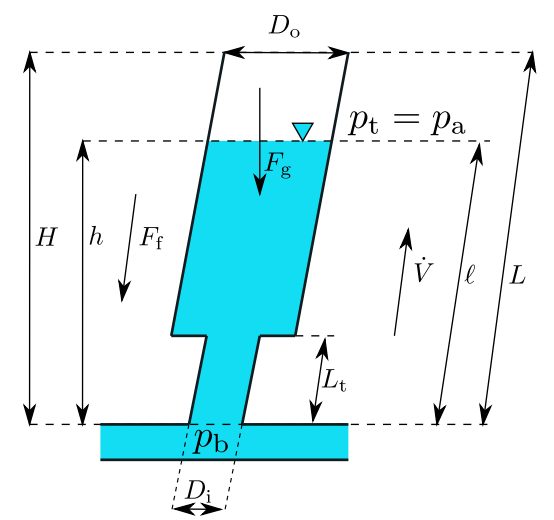

Figure 4. Throttle valve surge tank with the diameter and the length of throat as $D_{\mathrm{i}}$ and $L_{\mathrm{t}}$, respectively. The throat in the figure acts as a hydraulic obstruction for the water flow inside the surge tank.

The water mass, velocity, momentum, and the fluid friction force for a throttle valve surge tank varies depending upon the water level inside the surge tank as above or below the throat.

1. For $\ell \leq L_{\mathrm{t}}$ : When the water level is at the throat or below the throat, we have,

$$
\begin{aligned}
m & =\rho A_{\mathrm{t}} \ell \\
F_{\mathrm{f}} & =\frac{K^{\prime \prime \prime} A_{\mathrm{w}, \mathrm{t}} f_{\mathrm{D}}}{4},
\end{aligned}
$$

where $A_{\mathrm{t}}$ is the area of throat, $A_{\mathrm{w}, \mathrm{t}}$ is wetted area for the throat given by expression $A_{\mathrm{w}, \mathrm{t}}=\pi D_{\mathrm{t}} \ell$. The average velocity for this case is calculated using $v=\frac{\dot{V}}{A_{\mathrm{t}}}$ and $K^{\prime \prime \prime}$ is given by expression $K^{\prime \prime \prime}=\frac{1}{2} \rho v|v|$

2. For $\ell>L_{\mathrm{t}}$ : When water level inside the surge tank is above the throat of the surge tank, the frictional factor due to the throat should be considered.

The mass of the water inside the surge tank in this case is given as,

$$
m=\rho\left(A_{\mathrm{t}} L_{\mathrm{t}}+A\left(\ell-L_{\mathrm{t}}\right)\right),
$$

where $A=\frac{\pi D_{0}^{2}}{4}$. Similarly, the average velocity, water momentum, and pressure force are given as,

$$
\begin{aligned}
v & =\frac{\dot{V}}{2}\left(\frac{1}{A_{\mathrm{t}}}+\frac{1}{A}\right) \\
\mathscr{M} & =\rho \dot{V} \ell \\
F_{\mathrm{p}} & =\left(p_{\mathrm{b}}-\left(p_{\mathrm{t}}+\rho g\left(\ell-L_{\mathrm{t}}\right)\right)\right) A_{\mathrm{t}}+\rho g\left(\ell-L_{\mathrm{t}}\right) A .
\end{aligned}
$$

Observe that while considering the frictional force correction factor for $\ell>L_{\mathrm{t}}$ the velocity direction is important. a). For $v \geq 0$ : The friction factor is calculated considering a square expansion type pipe fitting and the generalized friction factor is given as (Lie, 2017a, p. 245)

For $N_{\mathrm{Re}}<4000$ :

$$
\phi_{\mathrm{se}}=2\left[1-\left(\frac{D_{\mathrm{o}}}{D_{\mathrm{i}}}\right)^{4}\right]
$$

For $N_{\mathrm{Re}} \geq 4000$ :

$$
\phi_{\mathrm{se}}=\left(1+0.8 f_{\mathrm{D}}\right)\left[1-\left(\frac{D_{\mathrm{o}}}{D_{\mathrm{i}}}\right)^{2}\right] \cdot 2
$$

This gives the total frictional force for this case,

$$
F_{\mathrm{f}}=\frac{K^{\prime \prime \prime} A_{\mathrm{w}} f_{\mathrm{D}}}{4}+\frac{1}{2} \rho v_{\mathrm{e}}\left|v_{\mathrm{e}}\right| A_{\mathrm{t}} \phi_{\mathrm{se}}
$$

where $\phi_{\mathrm{se}}$ represents the generalized friction factor for the square expansion type fitting. The entrance velocity for square expansion type fitting is expressed as $v_{\mathrm{e}}=\frac{\dot{V}}{A_{\mathrm{t}}}$ and the entrance area is $A_{\mathrm{t}}$. The wetted area is calculated using $A_{\mathrm{w}}=\pi D\left(\ell-L_{\mathrm{t}}\right)$.

b). For $v<0$ : The flow of water in this case is considered to be from the top of the surge tank to the bottom direction. The friction factor is calculated considering square reduction type pipe fitting and the generalized friction factor is given as,

for $N_{\operatorname{Re}}<2500$ :

$$
\phi_{\mathrm{sr}}=\left(1.2+\frac{160}{N_{\mathrm{Re}}}\right)\left[\left(\frac{D_{\mathrm{i}}}{D_{\mathrm{o}}}\right)^{4}-1\right]
$$

and for $N_{\operatorname{Re}} \geq 2500$ :

$$
\phi_{\mathrm{sr}}=\left(0.6+0.48 f_{\mathrm{D}}\right)\left(\frac{D_{\mathrm{i}}}{D_{\mathrm{o}}}\right)^{2}\left[\left(\frac{D_{\mathrm{i}}}{D_{\mathrm{o}}}\right)^{2}-1\right] .
$$

This gives the total frictional force for this case to be,

$$
F_{\mathrm{f}}=\frac{K^{\prime \prime \prime} A_{\mathrm{w}} f_{\mathrm{D}}}{4}+\frac{1}{2} \rho v_{\mathrm{e}}\left|v_{\mathrm{e}}\right| A \phi_{\mathrm{sr}},
$$

where $\phi_{\text {sr }}$ represents the generalized friction factor for the square reduction type fitting. The entrance velocity is expressed as $v_{\mathrm{e}}=\frac{\dot{V}}{A}$ and the entrance area is $A$.

\subsubsection{Air-cushion surge tank}

The general schematic of air-cushion surge tank is shown in Fig. 5. The free water surface inside the surge tank is filled with pressurized air making it as a closed type surge tank.

The pressure wave during a load rejection traveled from high pressure region (at the end of penstock) to the low pressure region (near free water surface, i.e., through the surge tank in hydro power systems). During this period, water mass inside the surge tank oscillates, dissipating pressure. The more the amplitude of water mass oscillation the higher should be the physical height of the surge tank. For reducing the amplitude of water oscillation inside the surge tank, pressurized air is placed inside the surge tank making a closed surge tank. This will cause the air to compress and expand adiabatically (Vereide et al., 2016; Zhang et al., 2009), and the energy due to high pressure is realeased as a form of work done for compression and rarefaction. For a adiabatic process we have,

$$
p V^{\gamma}=\text { constant }
$$




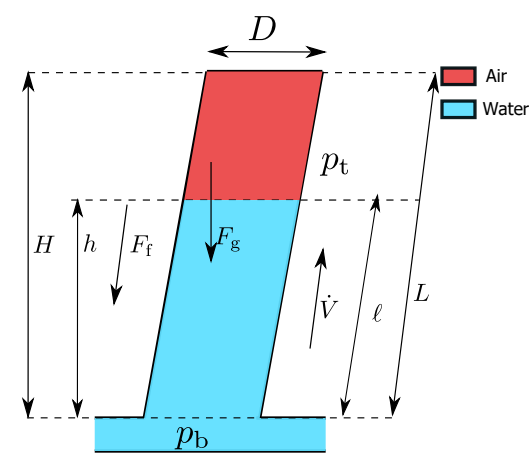

Figure 5. Air-cushion surge tank with initial air pressure of $p_{\mathrm{t}}$ which is normally tens of atmospheric pressure.

where $p, V$, and $\gamma$ is the pressure, volume, and ratio of specific heats at constant pressure and at constant volume, respetively, for air. The mechanistic model of air cushion surge tank is similar to that of simple surge tank, however with correction term for $m$ and $p_{\mathrm{t}}$ for a simple surge tank.

The mass of water and air inside surge tank is given as,

$$
m=\rho A \ell+m_{\mathrm{a}},
$$

and the air pressure inside the surge tank is given by,

$$
p_{\mathrm{t}}=p_{\mathrm{c}}\left(\frac{L-\ell_{\mathrm{o}}}{L-\ell}\right)^{\gamma}
$$

where $m_{\mathrm{a}}$ is the mass of air inside the surge tank given by expression,

$$
m_{\mathrm{a}}=\frac{p_{\mathrm{c}} A\left(L-\ell_{o}\right) M_{\mathrm{a}}}{R T^{o}} .
$$

In Eq. $25, p_{\mathrm{c}}$ is the initial air cushion pressure when initial slant height of liquid level inside the surge tank is $\ell_{0}$. The expression shown in Eq. 25 is derive from Eq. 23 equalizing the initial and final expression. In Eq. 26, $M_{\mathrm{a}}$ represents molar mass of air, $R$ is the universal gas constant, and $T^{\mathrm{o}}$ is the temperature of air inside the surge tank.

\subsection{Draft tube}

A draft tube is a hydraulic device used in reaction turbines in a hydro power systems for utilizing the available kinetic energy at the exit of the runner of the turbine. One of the prime benefits of a draft tube is to increase the turbine pressure head by decreasing the exit velocity out of the runner which will improves the overall efficiency of hydropower systems. And the other benefit is that the back flow of water from a tailrace to the turbine is restricted due to higher pressure region at the turbine's outlet due to draft tube (Gubin, 1973). There are various types of draft tubes; the most common type is a conical diffuser and others are variants of the conical diffuser (Arasu, 2008). In this paper, we will derive a mechanistic model for a conical diffuser and a hydraucone or a Moody spreading pipes (White, 1921).

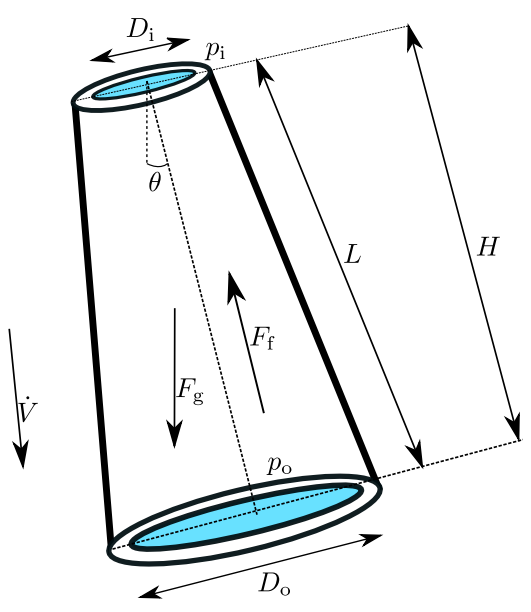

Figure 6. Conical diffuser inclined at angle $\theta$ with input diameter $D_{\mathrm{i}}$ and output diameter $D_{\mathrm{o}} . p_{\mathrm{i}}$ and $p_{\mathrm{o}}$ are input and output pressure of the conical diffuser with $p_{\mathrm{i}}>p_{\mathrm{o}}$.

\subsubsection{Conical diffuser}

A general schematic of the conical diffuser is shown in Fig. 6.

The influent and effluent mass flow of water through the conical diffuser is same. This gives $\frac{d m}{d t}=0$ from Eq. 1 . Thus, the mechanistic model is derived from the momentum balance given by Eq. 2 with series of DAEs. First, we consider the model of the conical diffuser considering it be a cylinder of average diameter $D=\frac{D_{\mathrm{i}}+D_{\mathrm{o}}}{2}$. Second, we will add a frictional force correction factor for the conical diffuser expanded from $D_{\mathrm{i}}$ to $D_{\mathrm{o}}$ (with a diffusion angle normally in the range of $\left(5^{\circ}-20^{\circ}\right)$ ).

$$
\begin{aligned}
\frac{d \mathscr{M}}{d t} & =\dot{\mathscr{M}}+F \\
M & =m v \\
v & =\frac{\dot{V}}{A} \\
\dot{\mathscr{M}} & =\dot{m} v \\
F & =F_{\mathrm{p}}-F_{\mathrm{g}}-F_{\mathrm{f}},
\end{aligned}
$$

where $F_{\mathrm{p}}=p_{\mathrm{i}} A_{\mathrm{i}}-p_{\mathrm{o}} A_{\mathrm{o}}, A_{\mathrm{i}}=\frac{\pi D_{\mathrm{i}}^{2}}{4}, A_{\mathrm{o}}=\frac{\pi D_{\mathrm{o}}^{2}}{4}, A=\frac{\pi D^{2}}{4}$, and $F_{\mathrm{g}}=m g \cos \theta$. The mass of water inside the diffuser is given by,

$$
m=\rho V,
$$

where $V$ is the volume of water. The expression for $V$ can be calculated as ${ }^{9}$,

$$
V=\frac{\pi H}{12}\left(D_{\mathrm{i}}^{2}+D_{\mathrm{o}}^{2}+D_{\mathrm{i}} D_{\mathrm{o}}\right)
$$

The overall frictional force is calculated using expression

$$
F_{\mathrm{f}}=\frac{K^{\prime \prime \prime} A_{\mathrm{w}} f_{\mathrm{D}}}{4}+\frac{1}{2} \rho v|v| A_{\mathrm{i}} \phi_{\mathrm{d}},
$$

\footnotetext{
${ }^{9}$ https://mathworld.wolfram.com/ConicalFrustum.htm
} 


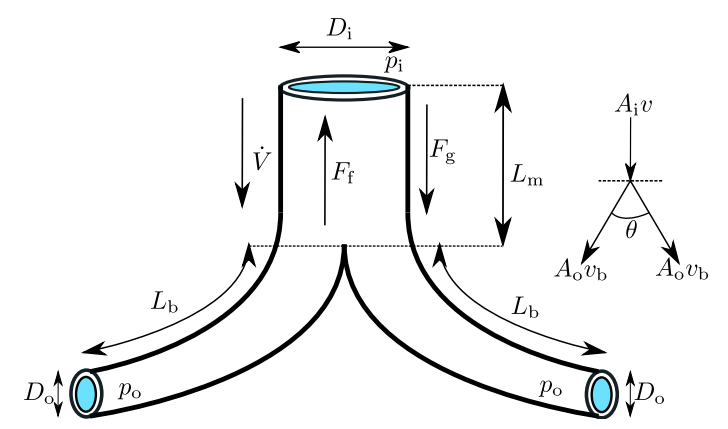

Figure 7. Moody spreading pipes with length of main part $L_{\mathrm{m}}$ with both the branch length of $L_{\mathrm{b}} . v$ and $v_{\mathrm{b}}$ are velocity through the main part and the branch part, respectively. The continuity equation for the pipe branching is $A_{\mathrm{i}} v=A_{\mathrm{o}} v_{\mathrm{b}}+A_{\mathrm{o}} v_{\mathrm{b}}$. The pipe contracts from the point of branching to the outlet of the branch in the real case of hydraucone as explain in (White, 1921, p. 276). However, we are considering a constant cross-section throughout the branch pipe. $\theta$ is a branching angle or a bifurcation angle.

where $\phi_{\mathrm{d}}$ is the generalized friction factor due to the diffusion.

The head loss for a conical diffuser, diffused from $D_{\mathrm{i}}$ to $D_{\mathrm{o}}$, is minimum at a diffusion angle of $8^{\circ}$ for a fixed value of $\frac{D_{\mathrm{o}}}{D_{\mathrm{i}}}$. For a pair value of diffusion angle and the ratio $\frac{D_{\mathrm{o}}}{D_{\mathrm{i}}}$, $\phi_{\mathrm{d}}$ can be calculated from (Munson et al., 2009, p. 420). For our case, for a maximum efficiency conical diffuser, we will conside a diffusion angle of $8^{\circ}$ which gives

$$
\phi_{\mathrm{d}} \approx 0.23\left(1-\frac{D_{\mathrm{i}}}{D_{\mathrm{o}}}\right)^{2}
$$

The mechanistic model of a conical diffuser can be represented by using DAEs from Eq. 27 to 33.

\subsubsection{Moody spreading pipes}

The schematic diagram of a moody spreading pipes or a hydraucone is shown in Fig. 7.

For Moody spreading pipes, $\frac{d m}{d t}=0$, and the mechanistic model is developed from the momemtum balance. We take the momentum balance considering verticle direction i.e., $y$-axis momentum conservation. The series of DAEs are,

$$
\begin{aligned}
\frac{d \mathscr{M}}{d t} & =\dot{\mathscr{M}}+F \\
\mathscr{M} & =m_{\mathrm{m}} v_{\mathrm{m}}+2 m_{\mathrm{b}} v_{\mathrm{b}} \cos \frac{\theta}{2} \\
\dot{\mathscr{M}} & =\dot{m}_{\mathrm{m}} v_{\mathrm{m}}+2 \dot{m}_{\mathrm{b}} \cos \frac{\theta}{2} \\
F & =F_{\mathrm{p}}-F_{\mathrm{f}}-F_{\mathrm{g}},
\end{aligned}
$$

where $m_{\mathrm{m}}$ and $m_{\mathrm{b}}$ are mass of water in the main part and the branching part, respectively given by expressions $m_{\mathrm{m}}=\rho A_{\mathrm{i}} L_{\mathrm{m}}$ and $m_{\mathrm{b}}=\rho A_{\mathrm{o}} L_{\mathrm{b}}$. Similarly, $v_{\mathrm{m}}$ and $v_{\mathrm{b}}$ are the velocity in the main and the branching part, respectively. $v_{\mathrm{m}}=\frac{\dot{V}}{A_{\mathrm{i}}}$ and $v_{\mathrm{b}}$ are calculated using continuity equation
Table 1. $\phi_{\mathrm{d}}^{\mathrm{o}}$ for different value of $\theta$ for Moody spreading pipes friction factor correction

\begin{tabular}{|c|c|c|c|c|c|}
\hline$\theta$ & 15 & 30 & 45 & 60 & 90 \\
\hline$\phi_{\mathrm{d}}^{\mathrm{o}}$ & 0.04 & 0.16 & 0.36 & 0.64 & 1 \\
\hline
\end{tabular}

for branching pipes using expression as,

$$
\begin{aligned}
A_{\mathrm{i}} v_{\mathrm{m}} & =A_{\mathrm{o}} v_{\mathrm{b}}+A_{\mathrm{o}} v_{\mathrm{b}} \\
A_{\mathrm{i}} v_{\mathrm{m}} & =2 A_{\mathrm{o}} v_{\mathrm{b}} \\
v_{\mathrm{b}} & =\frac{A_{\mathrm{i}}}{2 A_{\mathrm{o}}} v_{\mathrm{m}} .
\end{aligned}
$$

Furthermore, expressions for $\dot{m}_{\mathrm{m}}$ and $\dot{m}_{\mathrm{b}}$ are given as,

$$
\begin{aligned}
\dot{m}_{\mathrm{m}} & =\rho \dot{V} \\
\dot{m}_{\mathrm{b}} & =\rho \dot{V}_{\mathrm{b}} \\
\dot{V}_{\mathrm{b}} & =A_{\mathrm{o}} v_{\mathrm{b}},
\end{aligned}
$$

where $\dot{V}_{\mathrm{b}}$ is the volumetric flow rate in the brach.

The components in Eq. 37 are expressed as,

$$
\begin{aligned}
& F_{\mathrm{p}}=p_{\mathrm{i}} A_{\mathrm{i}}-2 p_{\mathrm{o}} A_{\mathrm{o}} \cos \frac{\theta}{2} \\
& F_{\mathrm{g}}=m_{\mathrm{m}} g+2 m_{\mathrm{b}} g \cos \frac{\theta}{2} .
\end{aligned}
$$

The fluid frictional force $F_{\mathrm{f}}$ is calculated considering fluid friction in the main and the brach pipe with addition of a generalized frictional force correction factor for branching. The overall frictional force is then,

$$
F_{\mathrm{f}}=F_{\mathrm{f}, \mathrm{m}}+2 F_{\mathrm{f}, \mathrm{b}} \cos \frac{\theta}{2}+2 \cdot \frac{1}{2} \rho v_{\mathrm{m}}\left|v_{\mathrm{m}}\right| A_{\mathrm{i}} \phi_{\mathrm{d}}
$$

where $\phi_{\mathrm{d}}$ is the generalized friction factor for a single branch in case of branching and taken from (Idelcik, 1966, p. 281, 301), given as,

$$
\phi_{\mathrm{d}}=1+\left(\frac{v_{\mathrm{b}}}{v_{\mathrm{m}}}\right)^{2}-2 \frac{v_{\mathrm{b}}}{v_{\mathrm{m}}} \cos \theta-\phi_{\mathrm{d}}^{\mathrm{o}}\left(\frac{v_{\mathrm{b}}}{v_{\mathrm{m}}}\right)^{2},
$$

where $\phi_{\mathrm{d}}^{\mathrm{o}}$ depends on $\theta$ and calculated from Table 1 .

$F_{\mathrm{f}, \mathrm{m}}$ and $F_{\mathrm{f}, \mathrm{b}}$ are fluid frictional force, calculated using Eq. 12, for main and the branch pipe for Moody spreading pipes.

Equation 34 to 41 represent DAEs for mechanistic modeling of Moody spreading pipes or Hydraucone.

\section{Simulated Responses and Results}

For the simulated responses from the mechanistic models of surge tank and draft tubes we take a case study from a real hydropower plant. For simulating open surge tanks and draft tubes we are using the layout of the Trollheim hydro power plant and for simulating air-cushion surge tank we are using the layout of the Torpa hydropower plant.

The layout diagram of Trollheim and Torpa hydro power plants are shown in Fig. 8. 


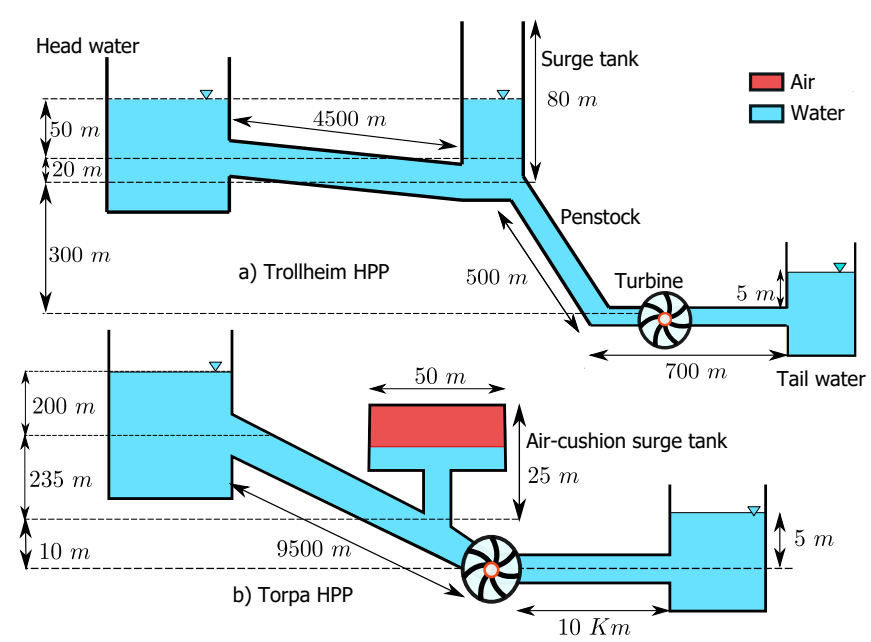

Figure 8. Layout diagram for the Trollheim (Vytvytskyi and Lie, 2019a) and the Torpa Hydro Power Plant (HPP) (Vereide et al., 2016). Nominal head, nominal discharge, and nominal power output are $370 \mathrm{~m}, 40 \mathrm{~m}^{3} / \mathrm{s}$ and $130 \mathrm{MW}$ for the Trollheim HPP, and $445 \mathrm{~m}, 35 \mathrm{~m}^{3} / \mathrm{s}$ and $150 \mathrm{MWfor}$ Torpa HPP. Torpa HPP has two turbine units each having nominal power output of $75 \mathrm{MW}$. The air-cushion surge tank for the Torpa HPP has air volume of $13,000 \mathrm{~m}^{3}$ initially pressurized at $4.1 \mathrm{Mpa}$. For the Trollheim HPP, the diameter for both of the penstock and the surge tank is $4 \mathrm{~m}$ while for both of the headrace and the tailrace tunnel is $6 \mathrm{~m}$. Similarly, for the Torpa HPP, the diameter of both of the headrace and the tailrace tunnel is $7 \mathrm{~m}$.

\subsection{Responses for surge tanks}

Figure 9 shows the simulated response for different surge tanks for the Trollheim HPP and the Torpa HPP.

In case of the Trollheim HPP, the manifold pressure surge during load acceptance ${ }^{10}$ in case of a simple surge tank has higher amplitude than that for sharp orifice and throttle valve surge tank. Furthermore, the pressure surge dies out soon in case of both sharp orifice and throttle valve surge tank. Also, the diameter of sharp orifice and throttle valve affects the manifold pressure surge oscillation. For example, when $D_{\mathrm{t}}=1 \mathrm{~m}$ for a throttle valve surge tank the manifold pressure $p_{\mathrm{b}}$ settles after $20 \mathrm{~s}$ while for sharp orifice type with $D_{\mathrm{so}}=1 \mathrm{~m}, p_{\mathrm{t}}$ settles around $300 \mathrm{~s}$.

In case of the Torpa HPP, the dynamics of both manifold pressure and air-cushion pressure is the same with a difference of almost 2 bars.

\subsection{Responses for draft tubes}

Figure 9 shows the simulated response for a conical diffuser and Moody spreading pipes for the the Trollheim HPP.

For a Moody spreading pipes draft tube, the inlet pressure $p_{\mathrm{i}}$ decreases as the branching angle decreases.

\footnotetext{
${ }^{10}$ It is the condition when the load at prime mover is added suddenly. For instance, in case of turbine running an electrical generator the sudden industrial operation like electrical motors, etc., can be considered as a load acceptance.
}
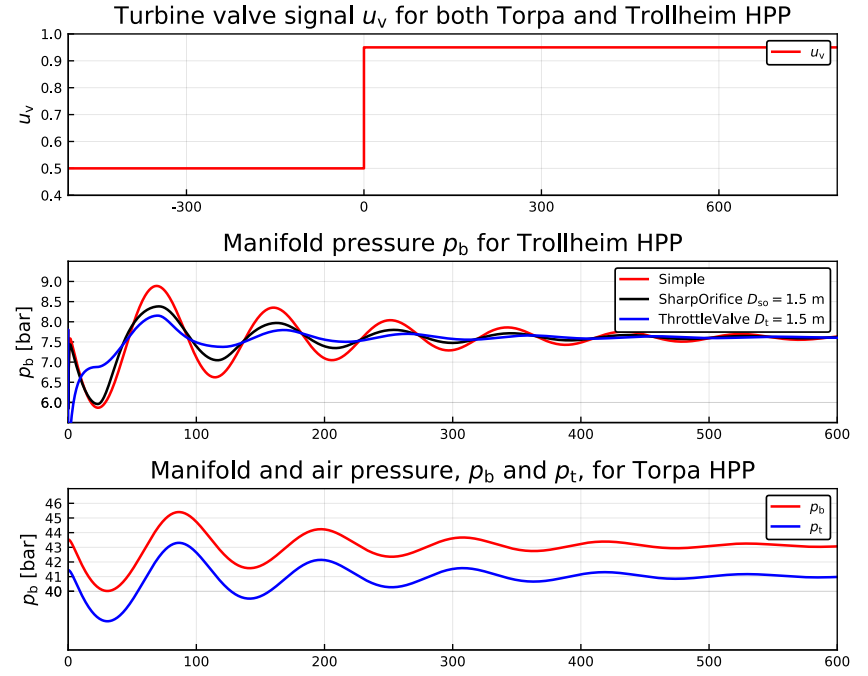

$p_{\mathrm{b}}$ for Sharp orifice surge tank with different $D_{\text {so }}$

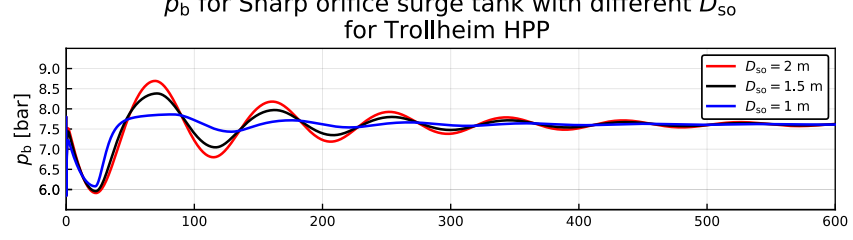

$p_{\mathrm{b}}$ for Throttle valve surge tank with different $D_{\mathrm{t}}$ for Trollheim HPP

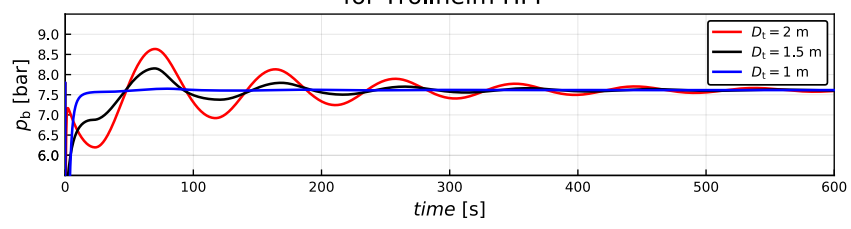

Figure 9. Simulated response for different surge tanks with step change of 0.45 to turbine's valve signal. The turbine's valve signal starts at $t=-500 \mathrm{~s}$ to show that simulation is performed in steady-state for $-500 \mathrm{~s}$ and at $t=0 \mathrm{~s}$ the valve signal is change from 0.5 to 0.95 to see the dynamics of other variables.

\section{Conclusions and Future Work}

This paper consists of mechanistic models for different types of surge tanks and draft tubes. Result shows that the pressure surge during load acceptance dies out soon for the throttle valve surge tank when the diameter of throat is decreased succesively. Similar operations can be obtained for a sharp orifice type surge tank, however, pressure surge amplitude decays soon in case of a throttle valve surge tank. For an air-cushion surge tank, the dynamics of both manifold pressure and air-cushion pressure are the same. For a Moody spreading pipes, the inlet pressure decreases when the braching angle is decreased.

Future work includes testing of the surge tank and draft tube mechanistic models with experimental data. The dynamics of sharp orifice type surge tank and throttle valve surge tank can be validated with simulated results from (Bhattarai et al., 2019). The air-cushion surge tank model can be validated with experimental results obtained from (Vereide et al., 2016). Similarly, model validation for the conical diffusers can be done with experimental data from 


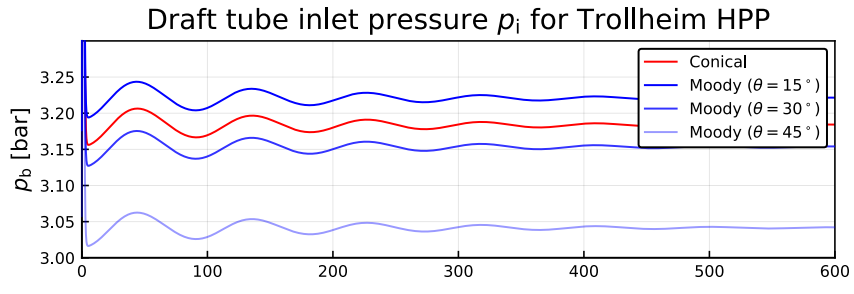

Figure 10. Simulated response for conical diffuser and Moody spreading pipes for different branching angle. $D_{\mathrm{i}}=4 \mathrm{~m}$ for both types of draft tubes. $D_{\mathrm{o}}=4.978 \mathrm{~m}$ for conical diffuser with diffusion angle of $8^{\circ}$ and $D_{\mathrm{o}}=3.5 \mathrm{~m}$ for Moody spreading pipes. $L_{\mathrm{m}}=4 \mathrm{~m}$ and $L_{\mathrm{b}}=3 \mathrm{~m}$ for Moody spreading pipes. Moody sprading pipes draft tube is simulated for different branching angle of $15^{\circ}, 30^{\circ}$, and $45^{\circ}$.

(Vytvytskyi and Lie, 2019a). For Moody spreading pipes, prior model judgement is required from experts.

\section{References}

A Valan Arasu. Turbo Machines. Vikas Publishing House, 2008.

Khem Prasad Bhattarai, Jianxu Zhou, Sunit Palikhe, Kamal Prasad Pandey, and Naresh Suwal. Numerical modeling and hydraulic optimization of a surge tank using particle swarm optimization. Water, 11(4):715, 2019.

R. Lester Brown. Plan B Updates - 107: The Great Transition, Part I: From Fossil Fuels to Renewable Energy । EPI, Aug 2012. http://www.earthpolicy.org/plan_b_updates/2012/update107.

CF Colebrook and CM White. Experiments with fluid friction in roughened pipes. Proceedings of the Royal Society of London. Series A-Mathematical and Physical Sciences, 161 (906):367-381, 1937.

Cyril Frank Colebrook, T Blench, H Chatley, EH Essex, JR Finniecome, G Lacey, J Williamson, and GG Macdonald. Correspondence. turbulent flow in pipes, with particular reference to the transition region between the smooth and rough pipe laws.(includes plates). Journal of the Institution of Civil engineers, 12(8):393-422, 1939.

Maksimillian Fedorovich Gubin. Draft tubes of hydro-electric stations. Published for the Bureau of Reclamation, US Dept. of the Interior and $\mathrm{a} \breve{S}, 1973$.

IE Idelcik. Handbook of hydraulic resistance: coefficients of local resistance and of friction. Technical report, ERDA Div. Phys. Res., 1966.

Bernt Lie. Modeling of Dynamic Systems, August 2017a. Lecture notes, Version of August 8.

BR Munson, DF Young, and TH Okiishi. Fundamentals of Fluid Mechanics, 2009.

Madhusudhan Pandey and Bernt Lie. The Role of Hydropower Simulation in Smart Energy Systems. 2020.

Valentyna Splavska, Liubomyr Vytvytskyi, and Bernt Lie. Hydropower systems: comparison of mechanistic and table look-up turbine models. In Proceedings of the 58th Conference on Simulation and Modelling (SIMS 58) Reykjavik, Iceland, September 25th-27th, 2017, number 138, pages 368373. Linköping University Electronic Press, 2017.

PK Swanee and Akalank K Jain. Explicit equations for pipeflow problems. Journal of the hydraulics division, 102(5), 1976.

Kaspar Vereide, Bjørnar Svingen, Torbjørn Kristian Nielsen, and Leif Lia. The effect of surge tank throttling on governor stability, power control, and hydraulic transients in hydropower plants. IEEE Transactions on Energy Conversion, 32(1):91-98, 2016.

Liubomyr Vytvytsky and Bernt Lie. Comparison of elastic vs. inelastic penstock model using OpenModelica. In Proceedings of the 58th Conference on Simulation and Modelling (SIMS 58) Reykjavik, Iceland, September 25th-27th, 2017, number 138, pages 20-28. Linköping University Electronic Press, 2017. doi:http://dx.doi.org/10.3384/ecp1713820.

Liubomyr Vytvytskyi. Dynamics and model analysis of hydropower systems. $\mathrm{PhD}$ thesis, University of SouthEastern Norway, 2019. URL http://hdl.handle. net $/ 11250 / 2608105$.

Liubomyr Vytvytskyi and Bernt Lie. Mechanistic model for Francis turbines in OpenModelica. IFAC-PapersOnLine, 51(2):103-108, 2018. doi:https://doi.org/10.1016/j.ifacol.2018.03.018.

Liubomyr Vytvytskyi and Bernt Lie. OpenHPL for Modelling the Trollheim Hydropower Plant. Energies, 12(12):2303, 2019a.

Liubomyr Vytvytskyi and Bernt Lie. Combining measurements with models for superior information in hydropower plants. Flow Measurement and Instrumentation, 69:101582, 2019b.

William M White. The Hydraucone Regainer, Its Development and Applications in Hydro-electric Plants. 1921.

Wikipedia. Nuclear power debate, Oct 2019. https://en.wikipedia.org/wiki/Nuclear_power_debate.

Xiaohong Zhang, Zhengfei Zhao, and Yanhang Zhang. Study on wave calculation of an air cushion surge chamber. In 2009 International e-Conference on Advanced Science and Technology, pages 70-73. IEEE, 2009. 